\title{
Circadian Output, Input, and Intracellular Oscillators: Insights into the Circadian Systems of Single Cells
}

\author{
J.J. Loros, ${ }^{* \dagger}$ J.C. DunlaP, ${ }^{\dagger}$ L.F. LaRrondo, ${ }^{\dagger}$ M. ShI,${ }^{\dagger}$ W.J. Belden,${ }^{\dagger}$ V.D. Gooch,${ }^{\ddagger}$ \\ C.-H. Chen,${ }^{\dagger}$ C.L. Baker,${ }^{\dagger}$ A. Mehra,${ }^{\dagger}$ H.V. Colot,${ }^{\dagger}$ C. SChwerdtFeger, ${ }^{\dagger}$ \\ R. Lambreghts ${ }^{\dagger}$ P.D. Collopy ${ }^{\dagger}$ J.J. Gamsby, ${ }^{\dagger}$ AND C.I. Hong ${ }^{\dagger}$ \\ *Department of Biochemistry, 'Department of Genetics, Dartmouth Medical School, Hanover, New Hampshire \\ 03755; 'Division of Science and Mathematics, University of Minnesota, Morris, Minnesota 56267
}

\begin{abstract}
Circadian output comprises the business end of circadian systems in terms of adaptive significance. Work on Neurospora pioneered the molecular analysis of circadian output mechanisms, and insights from this model system continue to illuminate the pathways through which clocks control metabolism and overt rhythms. In Neurospora, virtually every strain examined in the context of rhythms bears the band allele that helps to clarify the overt rhythm in asexual development. Recent cloning of $b a n d$ showed it to be an allele of ras-1 and to affect a wide variety of signaling pathways yielding enhanced light responses and asexual development. These can be largely phenocopied by treatments that increase levels of intracellular reactive oxygen species. Although output is often unidirectional, analysis of the $\mathrm{prd}-4$ gene provided an alternative paradigm in which output feeds back to affect input. prd-4 is an allele of checkpoint kinase- 2 that bypasses the requirement for DNA damage to activate this kinase; FRQ is normally a substrate of activated Chk2, so in Chk2 $2^{\mathrm{PRD}-4}$, FRQ is precociously phosphorylated and the clock cycles more quickly. Finally, recent adaptation of luciferase to fully function in Neurospora now allows the core FRQ/WCC feedback loop to be followed in real time under conditions where it no longer controls the overt rhythm in development. This ability can be used to describe the hierarchical relationships among FRQ-Less Oscillators (FLOs) and to see which are connected to the circadian system. The nitrate reductase oscillator appears to be connected, but the oscillator controlling the longperiod rhythm elicited upon choline starvation appears completely disconnected from the circadian system; it can be seen to run with a very long noncompensated 60-120-hour period length under conditions where the circadian FRQ/WCC oscillator continues to cycle with a fully compensated circadian 22-hour period.
\end{abstract}

\section{INTRODUCTION}

The innate ability to gauge time of day juxtaposed with the perception of environmental light represents one of the most widespread and closely coupled forms of cellular, tissue, and organismal regulation across a broad range of taxonomic groups. Changes in light fluence and wavelength are detected with the harvesting of photons by chromophore-binding photoreceptive molecules allowing immediate detection of important environmental changes. Biological rhythms provide organisms with the ability to anticipate environmental changes arising from the Earth's rotation. The physiological and molecular mechanisms of daily biological rhythms, called circadian rhythms, have been the focus of study for more than a century, but the past quarter century has witnessed a wealth of information explaining the basis of these clocks, with microbial systems playing a key role in many regards. All circadian clocks are cellular in nature, a property first described in microbes (Hastings and Sweeney 1958). More recently, the filamentous fungus Neurospora crassa and the fruit fly Drosophila melanogaster have pioneered the description of feedback loops as the molecular basis of circadian rhythmicity.

Scientists first became interested in circadian rhythmicity due to the broad spectrum of biological processes that are controlled by the clock, resulting in time-of-dayspecific activities and processes. Currently, a broad field of researchers has focused on studying these rhythms in many different organismal systems at many different lev- els. In the past two decades, much of the prominent work has focused on understanding molecular mechanisms involved in the core process that generates 24-hour rhythmicity, but understanding how the apparent daily time cues are perceived by the clock mechanism and then transduced into signals that regulate daily activities has more recently become of intense interest. The large and complex range of clock-regulated processes in multicellular organisms is well documented, although it is now understood that all of this complexity can be reduced to clock-regulated metabolism and physiology at the intracellular level (Loros et al. 2003), leading to a desire to understand the molecular underpinnings of intracellular regulation by circadian oscillators.

The well-understood filamentous fungus $N$. crassa has served as a basic model system to examine eukaryotic biology since the 1940s (Beadle and Tatum 1945), and it is also one of the earliest model systems to be shown to possess a bona fide circadian system (Pittendrigh and Bruce 1959). Close to two decades ago, we predicted that daily clock control of gene expression might be a major aspect of output (Loros et al. 1989). This has proved not only to be true for Neurospora, but also to be universally the case for all circadian systems (see, e.g., Liu et al. 1995; Harmer et al. 2000; Ceriani et al. 2002; Duffield et al. 2002; Panda et al. 2002). We performed the first systematic screen, using a novel technique at the time (subtractive hybridization), of two different mRNA populations, one isolated from morning and one from evening, to identify genes whose mRNAs were rhythmically abundant (Loros et al. 1989). These 
early genes were subsequently shown to be regulated at the level of transcriptional rate, suggesting that there would be cis-acting sequences in the promoter regions of these genes in addition to trans-acting factors that conferred circadian regulation (Loros and Dunlap 1991). Continuing studies using differential hybridization (Bell-Pedersen et al. 1996b), cDNA sequencing (Zhu et al. 2001), and cDNA and oligonucleotide microarrays (Correa et al. 2003; Nowrousian et al. 2003) have isolated several hundred more rhythmically regulated genes. Full-genome microarrays for the approximately 10,500 Neurospora genes have recently become available and are currently being used by more than one lab to examine clock regulation of gene expression at different points in the life cycle and under various growth conditions. In multicellular organisms, the identification of genes regulated by the clock was largely on a gene-by-gene basis until the advent of microarrays (Harmer et al. 2000; Duffield 2003) in addition to an innovative differential display protocol called ADDER used to isolate several cycling liver genes (Kornmann et al. 2001). These studies already have, and will continue to, dramatically improve our understanding of the global nature of circadian regulation on gene expression at the tissue and organ levels in plants and animals. Of great current interest is the mechanistic understanding of clock control of specific sets of genes at the level of individual cells, a more difficult problem to approach using in vivo samples. Adopting the same paradigms used in whole organisms, tissue cultures using individual cell types that display circadian properties (Balsalobre et al. 1998) have been recently leading the way (Duffield et al. 2002).

\section{THE CIRCADIAN CLOCK AND THE CIRCADIAN SYSTEM}

The haploid filamentous fungus $N$. crassa grows as incompletely septate, highly branched mycelia capable of fusing with separate but compatible strains, thereby comingling both cytoplasm and nuclei in a common cytoplasmic compartment. Neurospora is a superb organism for genetics and biochemistry with a well-defined genetic history, allowing the maintenance of lethal mutations, gene-dosage analysis, and complementation. The genome is about three times the size of yeast at $4.3 \times 10^{7}$ base pairs, encoding about 10,500 highly nonredundant genes expressed at different stages of the sexual and asexual life cycle. The clock in Neurospora is now monitored in a number of different ways. Historically and still of great utility is the monitoring of asexual conidiospore (conidia) development as the fungus grows on medium placed in hollow glass culture tubes called race tubes (Fig. 1) (Ryan et al. 1943). One consequence of growing in the enclosed environment of the race tube is that $\mathrm{CO}_{2}$ levels become elevated, resulting in suppression of conidiation and masking of the periodic formation of conidia within the tube. A mutation called band $(b d)$ (Sargent et al. 1966) overcomes this repression and has been used in Neurospora laboratory stocks in rhythm studies for the last 40 years. The $b d$ locus has recently been cloned and found, as expected, not to alter function of the clock's central mechanism, and also not completely surprisingly, it was found to have global effects on the regulation of clock out- put (Belden et al. 2007). For molecular and biochemical analysis, Neurospora is grown in liquid culture (Nakashima 1981; Perlman et al. 1981; Loros et al. 1989; Loros and Dunlap 1991; Aronson et al. 1994b; Garceau et al. 1997). Mycelial disks in liquid culture (Shi et al. 2007) maintain endogenous rhythmicity and phase, even upon transfer to solid medium. The ability to use luciferase (Morgan et al. 2003) to follow either in vivo transcriptional or translational fusions of rhythmically expressed genes has recently become a valuable tool to monitor clock progress by the complete codon optimization of firefly luciferase (Gooch et al. 2007).

\section{An Overview of the Circadian Oscillator}

Genetic, molecular, and biochemical analyses of the Neurospora clock have led to truly extraordinary advances in our understanding of much of the organism's circadian properties, including the generation and sustainability of rhythmicity, phase resetting by light and temperature, and the means by which the clock controls metabolism and behavior. The following is an extremely brief overview of the molecular underpinnings: In Neurospora, as in all eukaryotes studied to date, a critical part is played by an autoregulatory, molecular feedback loop between the FREQUENCY protein(s) (FRQ); the White Collar transcription factors (WC-1 and WC-2) (Aronson et al. 1994a,b; Crosthwaite et al. 1997; Dunlap 1999; Lee et al. 2003); and at least one other associated protein, FRH (Cheng et al. 2005). Expression at the frq locus is activated by the heterodimeric White Collar Complex (WCC) (Crosthwaite et al. 1995; Ballario et al. 1996, 1998; Linden and Macino 1997; Linden et al. 1997; Talora et al. 1999; Collett et al. 2001, 2002; Denault et al. 2001; Cheng et al. 2002). Long and short forms of FRQ (Garceau et al. 1997), produced from temperature-regulated alternative splicing (Colot et al. 2005; Diernfellner et al. 2005), then feed back to block activation of frq expression (Aronson et al. 1994b; Garceau et al. 1997; Merrow et al. 1997; Froehlich et al. 2003), resulting in rhythmic waves of both frq mRNA and FRQ protein, highly regulated by both phosphorylation (Garceau et al. 1997; Liu et al. 2000; Schafmeier et al. 2006) and ubiquitination (He et al. 2003, 2005) over the course of the 24-hour day. The environment signals to the clock, most notably via light and temperature, result in phase resetting such that the organism is in synchrony with the external world (Crosthwaite et al. 1995; Liu et al. 1998; Kramer et al. 2003; Price-Lloyd et al. 2005; Hunt et al. 2007) (for more a detailed overview, see Dunlap et al., this volume). Finally, the FRQ/WCC feedback oscillator can signal temporal information to the cell via daily changes in transcript abundance of pertinent output genes (Loros et al. 1989). A major regulatory means to this end is through cisacting sequences in promoters that confer daily changes of transcriptional rates (see, e.g., Loros and Dunlap 1991; Bell-Pedersen et al. 1996a).

\section{Noncircadian Oscillators}

Above, we alluded to the classic "input-oscillator-output" paradigm (Eskin 1979), but it is clear that organisms 

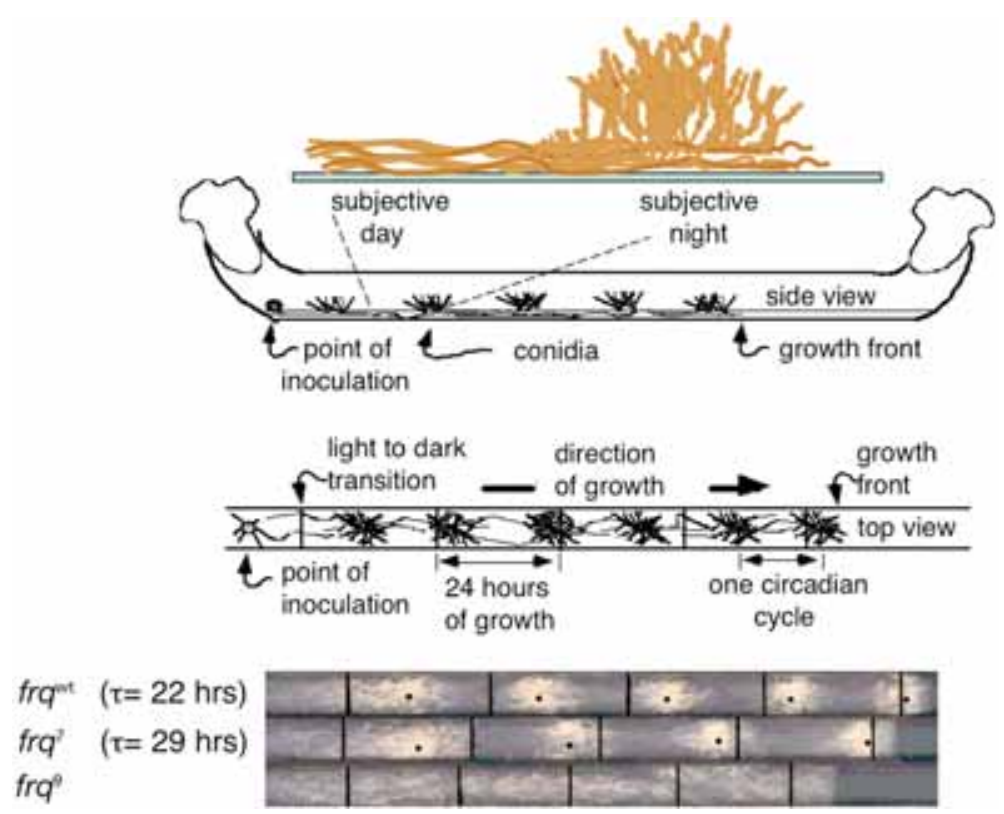

Figure 1. Analysis of Neurospora rhythms on race tubes. Glass tubes with growth medium are inoculated with fungal cultures on the left, grown for a day in the light, and transferred to darkness, which is interpreted as dusk (circadian time 12), synchronizing the circadian clock. As the culture grows, the clock controls development in the region of the growth front such that regions of undifferentiated surface hyphae alternate with regions of aerial hyphae over the course of the subjective day. The growth front leaves behind a region or "band" of aerial hyphae that will continue to differentiate into macroconidiospores, cell types biochemically distinct from the undifferentiated surface hyphae on either side. After several days of growth in constant darkness, the agar surface is covered with distinct conidial bands alternating with undifferentiated surface growth. The period length and phase of the clock are read from this pattern of growth, and mutants can be selected by screening for variations in the pattern. A long-period allele and loss-of-function allele of the frequency gene, $f r q^{7}$ and $f r q^{9}$, respectively, are shown. (Adapted, with permission, from Loros and Dunlap 2006 [C Springer-Verlag].)

contain a circadian system, not just an oscillator mechanism with linear inputs and outputs. Part of the system will doubtlessly include other oscillators (see, e.g., Dunlap and Loros 2004). As a field, regardless of organism, we are focusing more closely on individual cells, and as we do, examples of noncanonical rhythms are appearing more frequently. Oscillations can occur in any cellular pathway that has negative feedback regulation and a lag in at least one step, a common biological occurrence. Some of these oscillators will be unrelated and unconnected to the clock, and some may be part of the circadian system, either by having a necessary role in the clock oscillatory mechanism or by feeding into the clock, somewhere in the input or core oscillator, to alter properties of the clock. In addition, some will be "slave" oscillators (see below), controlled by the clock at some step within its own feedback to confer the properties of circadian period length and phase stability. Identification and elucidation of these alternative oscillators are major topics of interest to chronobiologists and are dealt with in depth below.

\section{OUTPUT FROM THE CLOCK IS THE NATURE OF TEMPORAL INFORMATION}

The utilitarian and therefore most important aspect of all clocks, often referred to as output, is the ability to invoke "time of dayness" onto the organism, such that it can predict daily changes in the environment to regulate its own changing metabolic needs over the course of the diurnal cycle. Most outputs may occur in a linear fashion and be distinct from the clock mechanism.

Neurospora has been developed as a paradigmatic system for understanding the physiological changes governed by the clock, including development of the hypothesis that changes in transcription would be a universal means by which the clock mechanism could regulate clock output. Testing this hypothesis led to the first genome-wide screens, using subtractive hybridization methodologies, for the daily changes in gene expression alluded to above and to coining the term "clock-controlled gene" (ccg) (Loros et al. 1989). The identity of hundreds of ccgs are currently known through a combination of differential hybridization, cDNA sequencing, cDNA and oligomer microarrays, and individual gene examination (Bell-Pedersen 2000; Correa et al. 2003; for review, see Loros et al. 2003; Nowrousian et al. 2003).

Isolation of the initial ccgs led to a first working model for defining output at the molecular level of gene expression. First, the endogenous rhythm of expression of a ccg would persist under constant conditions, reflecting control exerted by the clock, as opposed to external factors such as changes in light intensity. Second, a defining test was that the period length of the molecular rhythm would reflect the genotype of the strain. For example, in Neurospora, the first ccgs were shown to have changes in mRNA abundance with 22-hour period lengths in wild 
type and 29-hour period lengths when examined in the long-period strain $\mathrm{frq}^{7}$. The third initial criterion was that the inactivation of the ccg would have no effect on the clock, demonstrating that the gene represented a true molecular output in the circadian system as a whole. We now know that this third criterion is not universally true and although it may be true that most ccgs in any cell, tissue, or whole organism can be considered linear outputs, distinct from the mechanistic core of the oscillator mechanism, there exist important examples where an output can influence aspects of oscillator function, leading to coupled loops within the system.

With the early isolation of ccgs in several organisms, the question of ccg function emerged: What was the clock used for in different organisms and were there overlaps among organisms? It had been suggested that, as a general rule, clocks controlled "nonhousekeeping" processes that would be distinctly organism-dependent. This idea may have arisen due to the spectrum of output processes that had been studied before molecular analysis and that included such diverse biological functions as locomotor activity and behavior, leaf movement, asexual development, cardiovascular function, electrolyte balance, and timing of cell division. An observation surfacing from early clock genetics was that organisms were viable in the absence of operational clocks, leading to the thought that clock components, and possibly their regulatory outputs, would be found to be nonessential. We now know that virtually all aspects of biological function are controlled by the clock in Neurospora (Fig. 2) as well as in other systems examined (see, e.g., Liu et al. 1995; Harmer et al. 2000; Ceriani et al. 2002; Duffield et al. 2002; Panda et al. 2002; Wijnen and Young 2006). For example, the glycolytic gene encoding glyceraldehyde-3-phosphate dehydrogenase (GAPDH), the rate-limiting and first energy-harvesting enzyme in glycolysis, was identified early as a ccg in Neurospora (Bell-Pedersen et al. 1996b; Shinohara et al. 1998) and subsequently found in the dinoflagellate Gonyaulax (Fagan et al. 1999), chick retina (Bailey et al. 2004), mouse hepatocytes (Temme et al. 2000), and elsewhere (see, e.g., Iwasaki et al. 2004; Kamphuis et al. 2005).

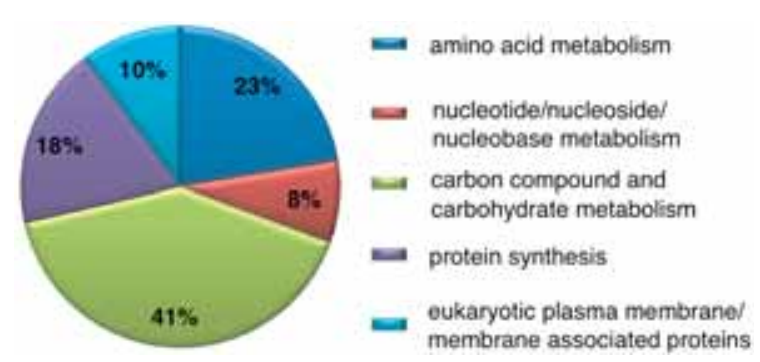

Figure 2. The clock regulates a broad variety of cellular functions in the Neurospora cell. RNAs were harvested over two circadian cycles and probed with oligomeric microarrays representing the approximately 10,500 genes from $N$. crassa. The results from two biologically independent sets of RNAs found $64 \%$ of the genes passed detection criteria with approximately $10 \%$ of those classified as clock-controlled genes (ccgs). About half of these displayed functional hits in the Functional Catalogue (http://mips.gsf.de/projects/funcat) (C.-H. Chen et al., unpubl.).

\section{THE SPECTRUM OF CCGS WITHIN A SINGLE CELL TYPE MAY REFLECT GROWTH/EXTERNAL CONDITIONS}

Certainly, GAPDH does not cycle in all cells nor under all conditions (Okamura et al. 1999; Kobayashi et al. 2004). An interesting feature of GAPDH, in addition to its role in glycolysis, is its ability to alter a cell's redox state through the reduction of $\mathrm{NAD}^{+}$to NADH. It may be that the clock is used to control GAPDH in specific cells or during specific oxidative/reduction conditions. In Neurospora, the spectrum of ccgs certainly reflects growth conditions. Early microarray studies identifying ccgs from high glucose (Nowrousian et al. 2003) versus lower glucose (Correa et al. 2003) cultures found largely nonoverlapping sets of cycling genes that ranged between $5 \%$ and $20 \%$, respectively, of all genes on the array.

A lesson about the plasticity of circadian gene regulation within a single cell type and within the organism can be deduced from the identity of the $b d$ gene, an allele commonly used in the background of laboratory stocks of Neurospora used for rhythms research. In the beginning years of Neurospora clock research, $b d$ was identified as a spontaneous mutation. It was shown not to alter the canonical properties of the clock, but to significantly enhance the conidiation rhythm when strains were grown on race tubes (Sargent et al. 1966). Since this time, virtually all circadian research has been performed with $b d$ containing strains (for review, see Dunlap and Loros 2005; Liu and Bell-Pedersen 2006), although $b d$ was known to display enhanced effects on both light and clock-regulated gene expression (Arpaia et al. 1993, 1995). A completed genome and single-nucleotide polymorphism (SNP) analysis fostered the identification of $b d$ as a T791I point mutation in ras-1 (Belden et al. 2007). RAS is a small, conserved, membrane-attached $\mathrm{G}$ protein, activated by exchange of GDP with GTP, which is modulated by guanine nucleotide exchange factors. It is a key player in numerous cellular signaling cascades, including those that link extracellular signals to gene expression (see, e.g., Mitin et al. 2005). The ras- $1^{\text {bd }}$ hypermorph is somewhat more active in GDP/GTP exchange than the wild type (Belden et al. 2007). Not unexpectedly, genes involved in asexual development were found to be upregulated in this altered function mutant. In addition, photo-induced expression of the $w c-1$ gene is also increased in the ras- $l^{\text {bd }}$ background. Importantly, in a ras $-1^{\text {bd }}$ background, the $\mathrm{C} 6$ zinc cluster transcription factor fluffy $(f l)$, which is both necessary and sufficient for asexual development (Bailey-Shrode and Ebbole 2004) and is itself rhythmically expressed (Correa and BellPedersen 2002), is expressed at significantly enhanced levels both after light exposure and rhythmically in the dark. This enhanced expression is the cause of the increased visibility of rhythmic conidiation in ras $^{\text {bd }}{ }^{\text {b }}$ containing strains (Fig. 3) (Belden et al. 2007).

While investigating the source of the ras $-1^{\text {bd }}$ signal that results in changes in expression of light and clock-regulated genes, we found that altering the amount of reactive oxygen species (ROS) could also influence the banding of wild-type strains in race tubes. ROS are increasingly rec- 

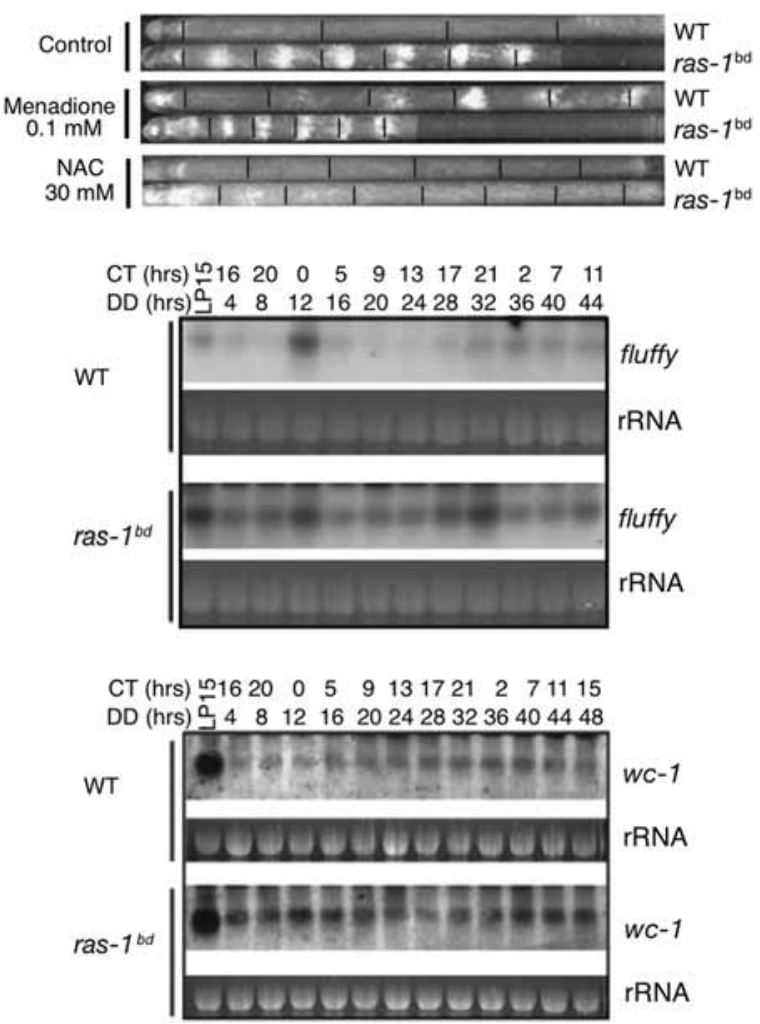

Figure 3. The expression of a transcription factor involved with

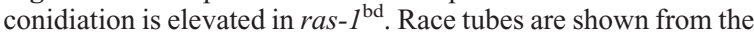
top down in groups of two: Wild type does not express rhythmic conidiation but band (= ras- $\left.I^{\mathrm{bd}}\right)$ does; adding menadione, an oxidant, to wild type results in banding but does not affect ras$I^{b d}$, other than slowing growth; adding the antioxidant $N$-acetyl cysteine (NAC) by itself eliminates banding in ras-1 $1^{\text {bd }}$, but has no effect on wild-type. Although reactive oxygen species (ROS) levels are not elevated in ras- $1^{\text {bd }}$, the mutant phenocopies changes in cellular ROS. Shown in the center and bottom panels are northern analysis of the transcription factors fluffy, required for conidiation in Neurospora, and wc-1, a core component in the Neurospora circadian system involved in clock regulation of conidiation. Both transcripts are up-regulated in the ras- $I^{\mathrm{bd}}$ strain. (Adapted, with permission, from Belden et al. 2007 [C Cold Spring Harbor Laboratory Press].)

ognized as important second messengers in cell signaling (D'Autréaux and Toledano 2007), and activated RAS is known to result in increased intracellular ROS levels (Irani et al. 1997). Conversely, changes in ROS may affect RAS signaling (see, e.g., Heo and Campbell 2006). The photoreceptor WC-1 and the clock component duplex WCC are thought to be sensitive to the redox states within the cell, as is carotenoid synthesis and development in Neurospora (Hansberg and Aguirre 1990). Additionally, increasing ROS levels may lead to increases in WCC transcriptional activity (Yoshida and Hasunuma 2004; Aguirre et al. 2005); all of these data suggest a credible connection among RAS signaling, cellular ROS levels, and clock-regulated gene expression. Coupled signaling between ROS and RAS in Neurospora has important implications for the study of circadian output regulation in all organisms. Significantly, conditions that alter metabolic state can result in different biological pro- grams and may alter the ccg profile even in a single cell type. It is well established that the known complement of ccgs is different in different tissues from multicellular organisms. The ras- $1^{\text {bd }}$ story indicates that within a specific cell or tissue type, changes in signaling or metabolic activity can alter the complement of genes regulated by the clock.

\section{SOME OUTPUTS FEED BACK TO MODULATE CLOCK FUNCTION, RESULTING IN ADDITIONAL LOOPS}

Most ccgs, when deleted from the system through gene inactivation, show no effect on clock function. However, some circadianly regulated outputs can change the workings of the clock. Two recent examples of different ways this can happen in Neurospora are detailed below. The first output feeds back to alter the way light information is received by the clock, and the second output feeds back to alter the biochemical nature of a clock component.

\section{A Molecular Output Can Feed Back to Input}

Research on Neurospora has had a leading role in understanding the molecular basis of how light resets the clock, a process called entrainment (Crosthwaite et al. 1995), and that includes gating (Heintzen et al. 2001). Much of the central mechanism of light entrainment in Neurospora is conserved in mammals (Shigeyoshi et al. 1997). Gating refers to the condition in which the clock regulates its own input such that it responds to an identical stimulus (e.g., a specific amount and wavelength of light) in nonidentical ways at different times of the circadian day. In gating, output and input become mechanistically merged. The $\mathrm{WC}-1$ protein is the primary blue light photoreceptor for Neurospora (Froehlich et al. 2002; He et al. 2002). A covalently bound FAD chromophore in the WC-1 light-oxygen-voltage (LOV) domain absorbs photons, leading to rapid and strong activation of frq transcription by the WCC in response to light input and to clock resetting (Crosthwaite et al. 1997). The strength of this frq-induction signal is modulated by another LOV domain containing photoreceptive protein called VIVID (VVD) that gates the light information coming into the clock at different circadian times (Heintzen et al. 2001). The expression of $v v d$ is clock-controlled, making $v v d$ both a $c c g$ and a clock input (Fig. 4). VVD is also responsible for the ability of Neurospora to sense changes in light intensity (Schwerdtfeger and Linden 2003; Schwerdtfeger et al. 2003), a process termed photoadaptation, and it additionally has a role in temperature compensation of phase (Heintzen and Liu 2007; Hunt et al. 2007). In response to light, a transient cysteine-flavin adduct forms in the LOV domain that promotes breaking of the hydrogen bonds holding an amino-terminal helix; this conformational change results in signaling (Zoltowski et al. 2007). In natural photoperiods of light and dark, the rhythmic output gene VVD effectively modulates the WCC transcriptional response to light on the frq promoter, permitting the clock to accurately keep time during 


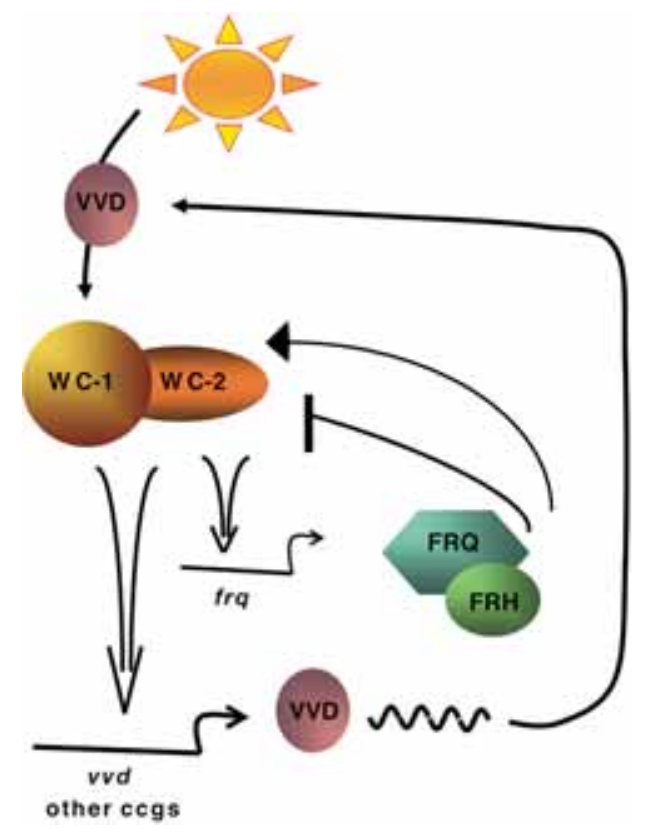

Figure 4. Coupled feedback loops within Neurospora may be part of the molecular mechanism of the clock or operate to connect output to input. Molecular clock components necessary for circadian rhythmicity, FRQ (Frequency), FRH (FRQ-interacting Helicase), WC-1 (White Collar-1), and WC-2 (White Collar-2), are shown in simplified coupled feedback relationships, acting through the $f r q$ promoter. The $v v d$ gene, a ccg, is clock-regulated at the level of mRNA abundance. The blue light photoreceptor VVD modulates the light information coming into the clock at different times of day, resulting in circadian gating.

the day until the dusk reset (Elvin et al. 2005). Rhythmic control of outputs that feed back onto LOV-domain-containing inputs or oscillator components (Kim et al. 2007) may turn out to be a functionally conserved mechanism to modulate clock properties, as LOV-domain-containing photoreceptors are widely found.

\section{A Molecular Output Can Directly Affect Clock Mechanisms}

In the case of VVD, a gene deletion results in a largely normal clock, albeit with defects in phase control, where it is clear that the oscillator mechanism itself is not greatly perturbed. A recent and surprising example of a clock-regulated output with the ability to conditionally feed into the oscillator came through the cloning of a genetic mutation that altered period length and temperature compensation. The prd-4 mutation was isolated in 1981 as a semidominant short-period-length mutation in Neurospora with a partial loss of temperature compensation (Gardner and Feldman 1981). Cloning and analysis of the gene responsible for this mutation in 2006 demonstrated prd-4 to encode the Neurospora checkpoint kinase-2 (Chk2) bearing a S493L mutation in the catalytic domain (Pregueiro et al. 2006). Chk2 is a threonine/serine protein kinase required for cell cycle arrest in response to DNA damage (Matsuoka et al. 1998). A null mutation constructed by gene replacement ( $p r d-4^{\mathrm{K} / \mathrm{O}}$ ) displayed a completely wildtype clock, with no apparent defects in either compensa- tion or period, although expression of $\operatorname{chk} 2$ was found to be under clock control (Pregueiro et al. 2006). It was apparent that Chk2 was not required for the clock, yet the results made it entirely unclear how the S493L mutation could alter clock function so dramatically.

In many organisms, the clock is known to gate the cell cycle. This is known as the "GET effect," for Gonyaulax, Euglena, Tetrahymena (Ehret and Wille 1970), and has additionally been shown in several animal tissues, although never for Neurospora. It is clearly established in many species that DNA damage results in cell cycle arrest (see, e.g., Harrison and Haber 2006) and that mutagens, through DNA damage, can affect the cell cycle. Although it was unknown if DNA damage could reset the circadian clock, $\gamma$-irradiation had been found to induced several important clock genes (Fu et al. 2002; Lee 2005), suggesting that this might be the case. Exposure to the radiomimetic drug methylmethane sulfonate (MMS) results in double-stranded DNA breaks and was found to reset the clock in wild type but not in the $\mathrm{prd}-4^{\mathrm{K} / \mathrm{O}}$ strain. When MMS was given at different times in the circadian cycle, the resulting phase-response curve (PRC) (Fig. 5) showed strong advance resetting during the subjective day in wild type but not in the $p r d-4^{\mathrm{K} / \mathrm{O}}$ strain (Pregueiro et al. 2006).

What appears to be happening is this: Whenever Chk2 becomes activated by DNA damage, one of its normal substrates is FRQ. Phosphorylation of FRQ promotes its turnover. In Chk $2^{\mathrm{PRD}-4}$, the mutation has resulted in a kinase with enhanced binding to FRQ, thereby partially bypassing the requirement for DNA damage to activate Chk2 as regards FRQ phosphorylation. As a result, in $\mathrm{Chk} 2^{\mathrm{PRD}-4}$, FRQ is always precociously phosphorylated and the circadian period length is shortened. Chk $2^{\text {PRD-4 }}$ is an example of a protein kinase not normally involved in operation of the clock but that regulates a clock protein in response to environmental damage to the cell.

\section{ALTERNATIVE OSCILLATORS AND DISSECTION OF THE HIERARCHICAL ORGANIZATION OF THE CIRCADIAN SYSTEM}

Oscillatory behavior is a major theme in living systems. Oscillations can naturally occur in any cellular pathway where there is negative feedback regulation with a lag. The vast majority of these oscillations do not meet the criteria for being a circadian rhythm. Much of the biochemistry of cellular metabolism can be described as feedback loops; many have short periods on the order of seconds and minutes, like feedbacks in the glycolytic oscillator, but many are also known with longer periods in the range of several hours. Often, such cycles are invisible because biochemical assays performed on a collection of cells, whether in a tissue or a dish, will report arrhythmicity if the cells are not in synchrony. Recall, for instance, that circadian rhythms in tissue culture were not found for years until the cells were appropriately synchronized (Balsalobre et al. 1998). As the clock field examines individual cells in more detail, such rhythms are appearing with greater frequency. One example of a long period but noncircadian, intracellular oscillation is the 5.5-hour sus- 

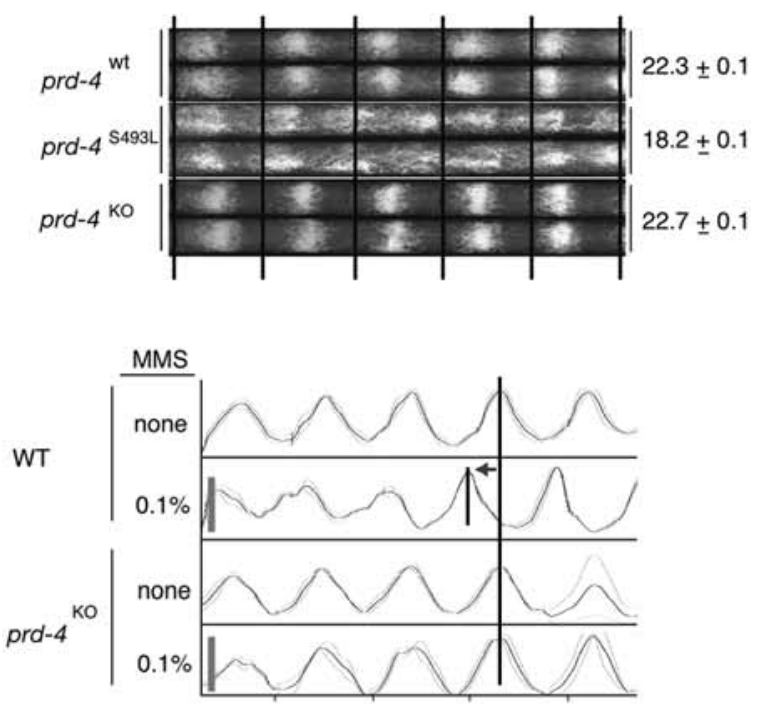

Days after transfer to dark

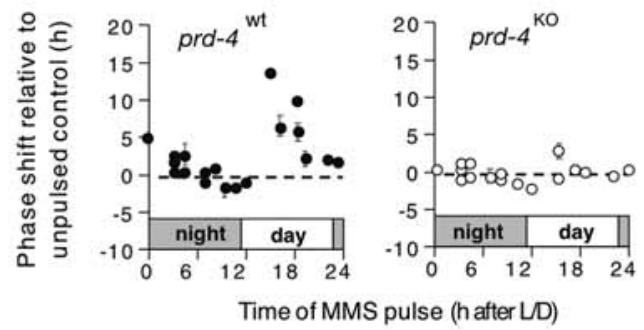

Figure 5. Clock resetting by a DNA-damaging agent requires Chk2(PRD-4). Race tubes (top) are shown in duplicate; wild type with an approximately 22-hour period length; the $c h k 2^{\text {prd-4 }}$ mutant allele (with a serine-to-leucine change at amino acid position 493 of Chk2) isolated due to the short, approximately 18 -hour-period length at $25^{\circ} \mathrm{C}$; and a gene replacement knockout of the chk2 gene showing a wild-type period length. (Middle) Traces from several race tubes illustrating that a 2-hour-long treatment with $0.1 \%$ methylmethane sulfonate (MMS), a radiomimetic DNA-damaging drug, phase-advances the clock in wild type but not in the $p r d-4^{\mathrm{ko}}$. A full phase-response curve (PRC) is shown (bottom), examining the effects of MMS treatment on circadian phase at different times over the subjective day. The wild-type strain at left is sensitive to and is reset by MMS at some times of day and not others. This response is lost in the $\mathrm{prd}-4^{\mathrm{ko}}$ strain, indicating that Chk2(PRD-4) is required for phase resetting in response to MMS. (Adapted, with permission, from Pregueiro et al. 2006 [C AAAS].)

tained oscillation in nuclear levels of the transcription factor $\mathrm{p} 53$, and its negative regulator Mdm2 that is seen upon $\gamma$-irradiation (Lev Bar-Or et al. 2000; Geva-Zatorsky et al. 2006). Other examples of infradian rhythms include the redox rhythmicity in yeast that has been modeled as a possible evolutionary origin of circadian rhythms (Tu and McKnight 2006).

Colin Pittendrigh and Victor Bruce (1959) first hypothesized a type of oscillation that might come under control of the circadian pacemaker, calling it a slave oscillator. They noted that "any feedback loop in the organism is a potential slave oscillator and if the circadian pacemaker can make input to the loop, the slave will assume a circadian period and become a part of the tem- poral program that the pacemaker drives" (Pittendrigh 1981). Are there actually slave oscillators in Neurospora or other organisms? In many organisms, regulatory relationships among factors involved in nitrate assimilation can give rise to a feedback loop, such that nitrate reductase activity is rhythmic, first shown in Gonyaulax (Ramalho et al. 1995). Possibly, the best-described putative slave oscillator is the nitrate reductase (the NIT3 protein) rhythm in Neurospora (see, e.g., Lillo et al. 2001), the metabolic activity that regulates the conversion of assimilated nitrate to ammonia and then to glutamine in a negative feedback loop. NIT3 activity is rhythmic not only in wild-type strains, but also in frq-null and probably $w c-1$-null strains, and interestingly, even in constant light when the FRQ/WCC is not rhythmic (Fig. 6) (Christensen et al. 2004). Preliminary work examining nitrogen reductase activity at different temperatures gives some indication that the period length of the rhythm in a wild-type strain shows temperature compensation that may then be lost in the absence of FRQ/WCC. This would suggest that coupling to the clock allows the nitrogen reductase rhythm to display circadian characteristics of period length, compensation, and phase control in clock wild-type strains.

\section{FRQ-LESS OSCILLATORS AND OTHER NONCIRCADIAN FEEDBACK LOOPS}

Ancillary oscillators exist in organisms without functional circadian clocks and may display some circadian properties, but do they represent part of the working clock mechanism? Genetic, molecular, and biochemical approaches aimed at understanding FRQ/WCC regulatory loops have been highly successful in providing major insights into such canonical clock oscillator features as the production and maintenance of rhythmicity, light and temperature resetting, and phase control with respect to the physical diurnal cycle. Nevertheless, within any organism, there is a complex circadian system that is thought to encompass other feedbacks that result in oscillatory behavior. Some of these will be feedback loops with functions distinct from the clock mechanism. Some of these will be clock-regulated, and some will be examples of clock-regulated output that feeds back to some aspect of the clock, either directly to mechanism or to input as discussed above for Chk $2^{\text {PRD-4 }}$ and VVD. In Neurospora, oscillators that are unmasked when the FRQ/WCC feedback loop is eliminated have been referred to as FRQ-less oscillators or FLOs (Iwasaki and Dunlap 2000). To date, several FLOs have been identified, although their importance in terms of clock function has yet to be established. Among the fungi, a number of noncircadian rhythms in development have been described (for review, see Bünning 1973) in otherwise wild-type strains. An early example is the clock strain (Sussman et al. 1964, 1965), identified as producing a rhythm in growth when cultured in race tubes, but later shown to not be circadian (Feldman and Hoyle 1974).

More than two decades ago, a FLO rhythm was found in a clock-defective strain, fr $q^{9}$ (Loros 1984; Loros and Feldman 1986), that makes a truncated and nonfunctional 

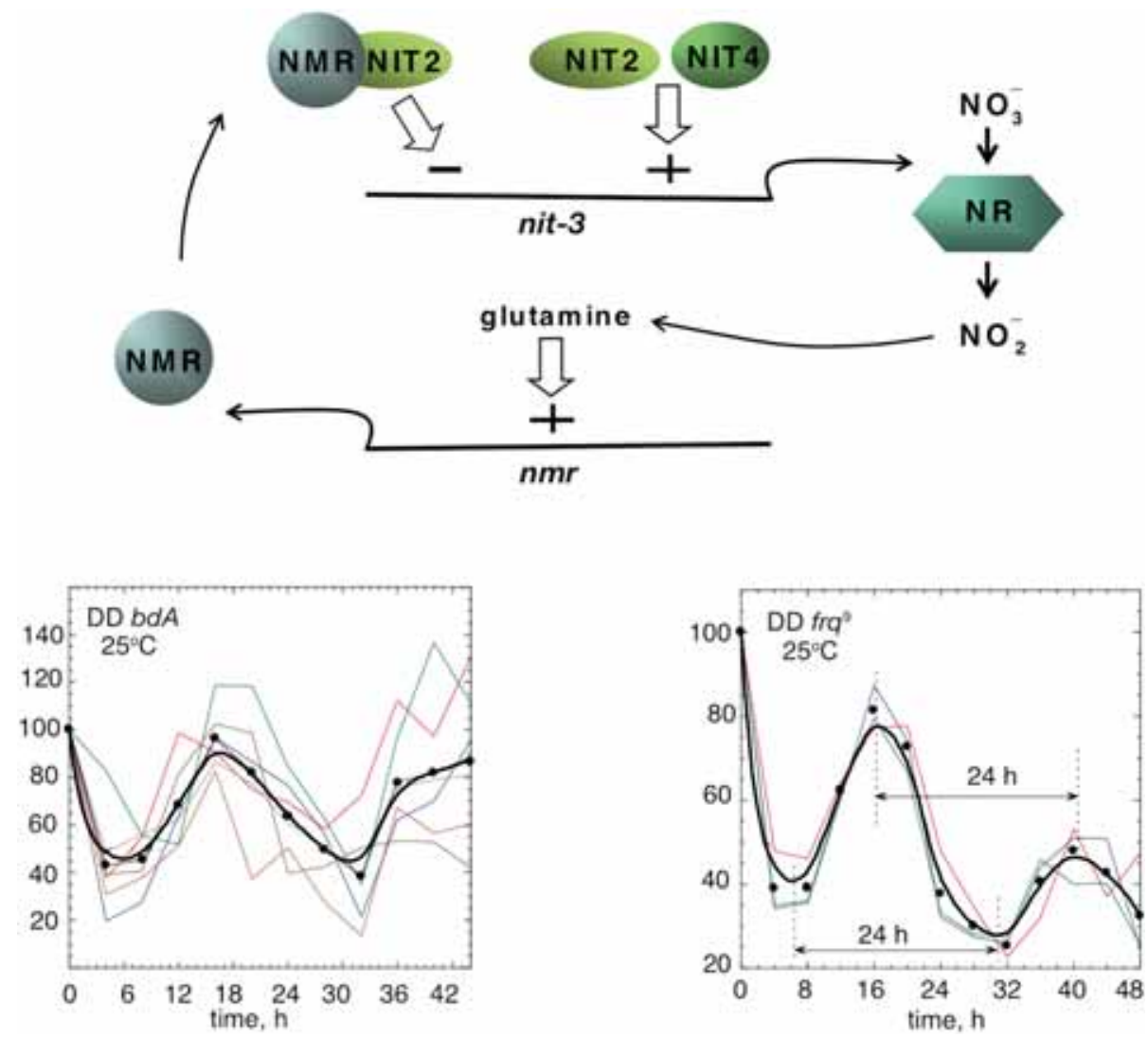

Figure 6. Nitrate reductase may be a slave oscillator. (Top) The effectors of nitrogen assimilation describe a negative feedback loop when nitrate is the sole carbon source. The positive regulators NIT2 and NIT4 are required for the expression of the nit-3 gene encoding the nitrogen reductase (NR) enzyme. NR catalyzes the reduction of nitrate to nitrite, which is eventually converted to glutamine, thought to induce expression of the nitrogen metabolite regulator (NMR). NMR binds directly to NIT2, resulting in the inhibition of nit-3 expression. NR activity displays endogenous oscillations with a period length of approximately 24 hours in constant darkness in both wild-type and loss-of-function $f r q$ alleles at $25^{\circ} \mathrm{C}$ (bottom). The loss-of-function $f r q^{9}$ strain may show changes in period length at other temperatures. (Bottom adapted, with permission, from Christensen et al. 2004 [@ Sage Publications].)

version of the FRQ protein (Aronson et al. 1994a). Although the period length of the FLO-driven rhythm in conidial development can range from 12 to 34 hours, it can be manipulated to occur within the circadian range because the period is highly sensitive to changes in both temperature and nutrition. Several other FLOs have since been described (see, e.g., Mattern and Brody 1979; LakinThomas 1998; Merrow et al. 1999; Correa et al. 2003; Granshaw et al. 2003; Christensen et al. 2004; dePaula et al. 2006; Lombardi et al. 2007; for review, see Dunlap et al. 2004; Vitalini et al. 2006), but none display the complete set of formal circadian properties nor have they been shown to affect the operation of the FRQ/WCC feedback loop. However, FLOs may exhibit some circadian properties (see, e.g., dePaula et al. 2006). The extent to which a particular FLO might be a manifestation of the circadian mechanism revealed by the removal of some clock components is an appealing idea, particularly because the appearance of noncircadian and ultradian rhythmic behavior has been found following genetic lesion of clock genes in other systems (see, e.g., Dowse et al. 1987; HamblenCoyle et al. 1989; Liu et al. 2007; Storch et al. 2007).

The Drosophila circadian system has been modeled to contain a master oscillator that drives or entrains slave oscillators directly involved with outputs (Pittendrigh and Bruce 1959), a model that may be pertinent to Neurospora (Iwasaki and Dunlap 2000; Merrow et al. 2001; Dunlap and Loros 2006) and other systems. Pittendrigh speculated that the use of several slave oscillators by the core clock would allow some aspects of the system to be open to evolutionary adjustment without altering other component parts and that the slaves, because they would normally be entrained by the master, need not have all circadian properties (Pittendrigh 1981). A reasonable interpretation of FLOs is that they represent a set of Pittendrighian slave oscillators coupled to the FRQ/WCC master oscillator; when the master oscillator is removed, the slaves run on their own in various noncircadian or partially circadian modes (Loros and Dunlap 2001; Dunlap and Loros 2004, 2005, 2006). A major and untested caveat to this model is that most FLO components have not been molecularly identified and therefore cannot be compromised or deleted to test for effects on the FRQ/WCC oscillator, so their involvement in the clock system is to date unanswered. Figure 7 summarizes the currently understood interrelationships among oscillators.

The most extensively studied FLO is the asexual 


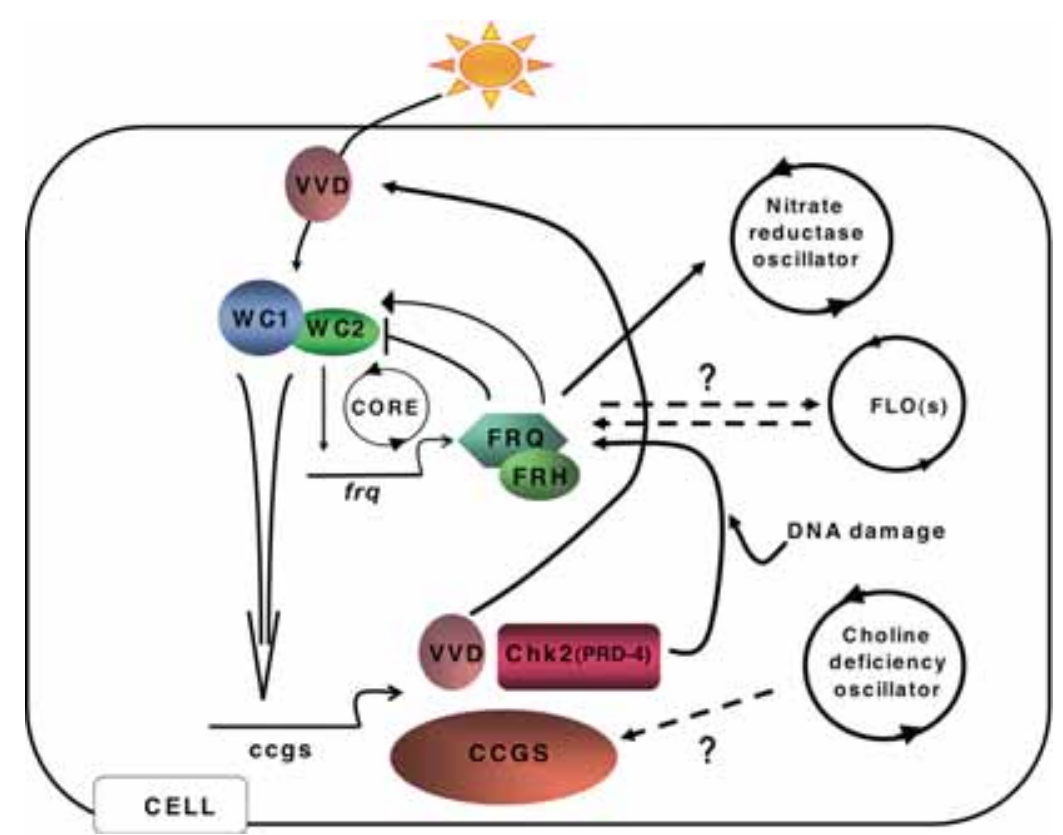

Figure 7. The circadian system is a collection of oscillators generating time information, integrating this with environmental information, whose function is to coordinate the life of the Neurospora cell. An expansion of Figure 4, this schematic is a representation of the relationships within the circadian system as a whole. Chk2 (checkpoint kinase-2) is shown as a ccg that can feed back, under conditions of DNA damage, to phosphorylate the clock component FRQ, thereby altering the phase of the clock. The nitrate reductase feedback loop is depicted as a classic slave oscillator, not required for clock function but under clock control. The choline deficiency oscillator is shown as an independent oscillatory system that may influence genes that are also clock-regulated. Finally, the FLO oscillator(s), where no molecular underpinnings are known, has unknown connections to the clock, but information in either direction may exist.

developmental rhythm that persists in the absence of FRQ (Loros and Feldman 1986; Loros et al. 1986; Aronson et al. 1994a). Under constant conditions, the rhythm only appears sporadically and under limited and specific conditions. The period can range from 12 to 35 hours depending on culture conditions, and phase is not maintained between individual cultures, reflected in the large standard deviation of the period length. The rhythm is not entrainable by light, but if it is the same FLO as that described by Merrow et al. (1999), it is entrained by temperature. It has been modeled as either a slave oscillator (a reflection of residual circuitry of the clock), not involved in the circadian system at all (Loros and Dunlap 2001; Dunlap and Loros 2004; see, e.g., Christensen et al. 2004), or as the underlying rhythm generator core to the circadian oscillator (Roenneberg and Merrow 1998; Merrow et al. 2001; Lakin-Thomas 2006a). Although a consortium of labs found the rhythm to be driven by temperature rather than entrained, as evidenced by peaks of development limited to the cold phase of a temperature cycle, and reported that the conidiation rhythm stopped as soon as the temperature cycle stopped (Pregueiro et al. 2005), others found the temperature cycle itself resulted in masking of a weaker, nonsustainable but entrainable component (Roenneberg et al. 2005; Lakin-Thomas 2006a). Despite all of the effort, the question of this FLO's potential role in any part of the circadian system remains unanswered. This will likely continue to be the case until a genetic or biochemical basis for the FLO is discovered, allowing it to be molecularly examined and disabled.

\section{ANCILLARY OSCILLATORS CAN AFFECT THE SAME OUTPUTS AS THE CLOCK AND CAN MASK CIRCADIAN CONTROL}

Work begun in the late 1970s described conidial banding rhythms in fungal strains with defects in lipid metabolism. One of these was called cel, a fatty acid chain elongation mutant that had defective circadian properties in period length and temperature compensation of the conidiation rhythm (see, e.g., Mattern and Brody 1979). Another mutant, chol-1, a morphological strain reparable by addition of choline, showed large changes in linear growth under limiting choline, manifesting as a rhythm in conidiation with extraordinarily long periods sometimes exceeding 100 hours (LakinThomas 1996, 1998). Both the choline-starvation-induced and the cel rhythms, plus a recent mutation called ult (Lombardi et al. 2007), were shown to be largely independent of the FRQ/WCC oscillator. An interpretation has been that the FRQ/WCC feedback is dispensable in determinating conidiation period length and therefore that this feedback loop is not required for circadian rhythmicity (Lakin-Thomas 1998; Lakin-Thomas and Brody 2000), but instead provides input into the system (Lakin-Thomas 1998, 2006b). Another explanation is that perhaps lipid manipulations can change the coupling between the FRQ/WCC and FLO oscillators (Granshaw et al. 2003; Lombardi et al. 2007). An underlying assumption in this work is that the rhythm in conidiation is a true representation of the circadian oscillator, although as discussed above, not all developmental rhythms dis- 
played by Neurospora are circadian nor are they necessarily even regulated by the circadian system.

To acquire a clearer picture of the FRQ/WCC oscillator with regard to these other oscillators, it is necessary to be able to follow both in the same culture over the same time frame. In this case, the activity of the FRQ/WCC feedback needed to be monitored at the same time that the long-period, choline-limited rhythm of conidiation was being expressed. This became possible with the development of a codon-optimized luciferase that has activity in Neurospora (Gooch et al. 2007). Using the frq promoter to drive luciferase expression allows the FRQ/WCC oscillator to be monitored under conditions when it no longer controls conidiation. Using luciferase to follow frq expression in race tubes of the chol-1 strain under limiting choline showed the chol-1, frqP-luc strains replicating a long-period rhythm in conidiation of about 78 hours; this rhythm was frq-independent, as previously shown. A strain, chol-1, $\mathrm{frq}^{7}$, frqP-luc, carrying the long-period $\mathrm{frq}^{7}$ allele, showed a similar long-period rhythm of development on the race tube. However, when luciferase was monitored, the activity showed a clear 22-hour rhythm in the $\mathrm{rrq}^{+}$strain and a long-period, 29-hour rhythm in the chol-1, frq ${ }^{7}$, frqP-luc strain (Fig. 8). The choline-starvation-induced rhythm is known not to be temperature-compensated (Lakin-Thomas 1998), but the luciferase activity rhythm in the chol-1, frqP-luc strain demonstrated temperature compensation, equivalent to the temperature compensation of the FRQ/WCC oscillator (Shi et al. 2007). These experiments unequivocally demonstrated that the FRQ/WCC oscillator is functionally wild type under choline starvation in the chol-1 strain, but it is no longer controlling the timing or expression of asexual development. These observations indicate that the choline-starvation-induced rhythm may reflect morpho- logical cycles that mask or uncouple the circadian oscillator from development. It is clear, in the case of chol-1, that two distinctly different rhythms can coexist in the same culture, be of very different periodicities, and therefore not be controlled by the same oscillatory system (Fig. 7).

\section{CONCLUSIONS}

Circadian output comprises the functional end of circadian systems in terms of adaptive significance. Among fungi and animals, the regulatory logic of the core transcription-translation feedback loop is similar, and even in plants, where the core mechanism contains additional interlocked loops, a principal and primary form of output is the daily clock regulation of gene expression. For this reason, work on Neurospora, which pioneered the analysis of clock-controlled genes, continues to illuminate the pathways through which clocks can control metabolism and overt rhythms.

In addition to providing an overview of output in Neurospora, we have developed three recent stories. The first described the cloning of the $b d$ gene and its identification as an allele of ras-1. In Neurospora, virtually every strain examined in the context of rhythms bears the $b d$ allele that helps to clarify the overt rhythm in asexual development. ras $-1^{\text {bd }}$ influences a wide variety of signaling pathways and results in both enhanced light responses and increased asexual development, altering the profile of ccgs in the cell and organism. Interestingly, both of these can be largely phenocopied by treatments that increase levels of intracellular reactive oxygen species.

A second story provides an example of an output from the clock that feeds back to affect circadian input. Cloning of prd-4 showed it to be an allele of checkpoint kinase-2. Normally, Chk2 is quiescent until it is activated by
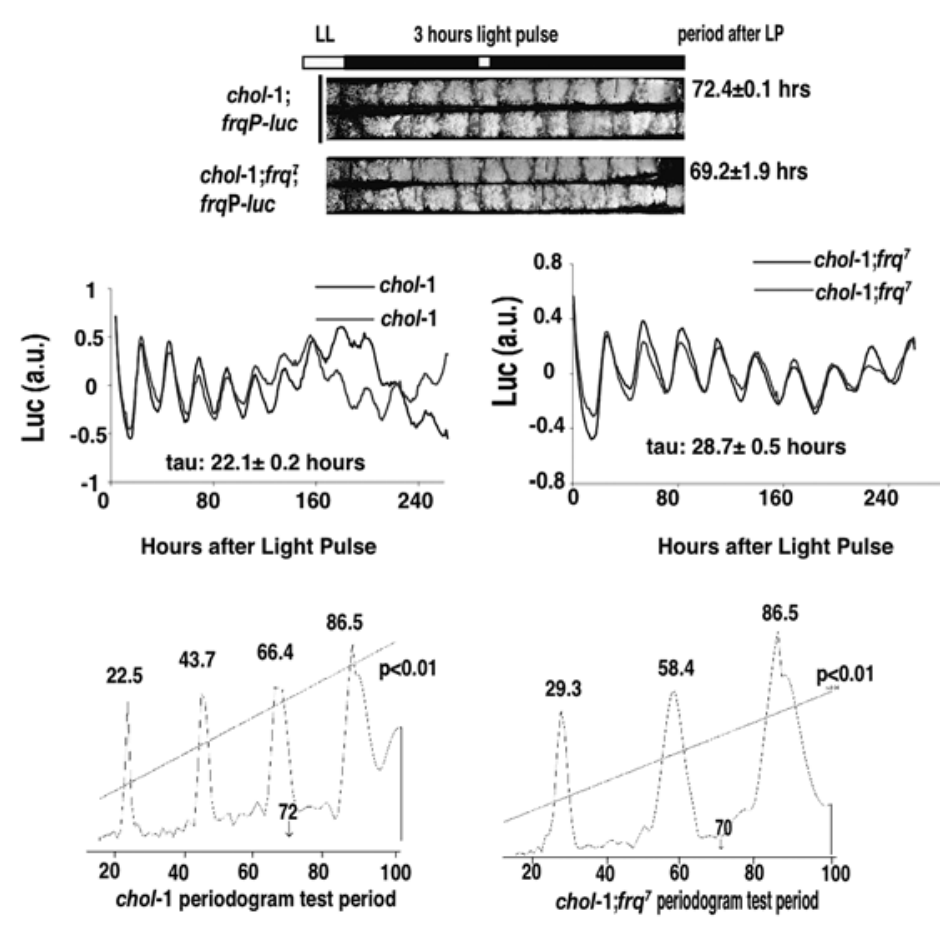

Figure 8. $f r q$ allele-dependent luciferase rhythms are circadian in long-period chol-1 strains. Race tubes containing $12.5 \mu \mathrm{M}$ luciferin and the chol$1, \mathrm{frq}^{+}$or $c h o-1, \mathrm{frq}^{7}$ strains, both bearing a transcriptional fusion of the frq promoter to an optimized luciferase gene (top). Note the characteristically long period of development in the chol-1 strains. Detrended signals in bioluminescence from each race tube express about 22- and 29-hour rhythms in the chol-1, frq ${ }^{+}$or chol-1, frq ${ }^{7}$ strains, respectively (middle), running in the same cultures expressing the approximately 70 -hour rhythms in development. The luciferase data were subjected to periodogram analysis (bottom), demonstrating strong 22.5-hour (wild-type) and 29.3-hour $\left(\right.$ frq $\left.^{7}\right)$ period components. The ability to follow both chol-1 and frq rhythms has exposed independent oscillators in a common cytoplasm. (Reprinted, with permission, from Shi et al. 2007 [@ National Academy of Sciences].) 
ATM/ATR following DNA damage, and once activated, it phosphorylates a number of target genes, one of which is FRQ. The mutation in the Chk2 $2^{\text {PRD-4 }}$ variant causes Chk2 to bypass the requirement for DNA damage to activate this kinase; as a result, FRQ is always precociously phosphorylated, resulting in more rapid turnover and a faster cycling clock with a short-period length. In the wild-type clock, Chk2 phosphorylates FRQ in response to DNA damage in a time-of-day-dependent manner, resulting in clock-regulated phase shifting.

Finally, with improved methods for the study of single cells and the synchronization of cells in culture, more and more noncircadian or circadian-coupled feedback loops are being described. Arguably one of the most closely examined circadian cells is Neurospora, in which at least nine distinct oscillators have been described in addition to the circadian FRQ/WCC loop. In clock wild-type cells, many of these are normally coupled to the clock and run with circadian period lengths, but when the clock is lesioned, for instance, through mutation of frq or $w c$ genes, these FLOs can continue to cycle on their own. In doing so, some retain circadian characteristics, suggesting the possibility that they, like the FRQ/WCC loop, contribute to the core circadian oscillator. As long as the core feedback loop could be followed for long periods only through its control of the banding rhythm, it was difficult to study the FRQ/WCC loop simultaneously with other loops. However, the recent adaptation of luciferase to function at high levels in Neurospora now allows the core FRQ/WCC feedback loop to be followed in real time under conditions where it no longer controls the overt rhythm in development. This ability can be used to describe the hierarchical relationships among FLOs to see which are connected to and influence the circadian system. The nitrate reductase oscillator appears to be connected to the clock. In contrast, an interesting example arose from analysis of the oscillator controlling the long-period rhythm elicited upon choline starvation. This oscillator runs with a long 60-120-hour period length in conidia formation that is not compensated against changes in temperature or nutrition, however; the circadian FRQ/WCC oscillator continues to cycle with a fully compensated circadian 22-hour period. Over many days, the two oscillators cycle through all phase relationships with respect to one another, and periodogram analysis shows no influence of the choline deficiency oscillator (CDO) on the circadian cycle. These data strongly suggest that the $\mathrm{CDO}$ is an ancillary loop that can assume control of normally clock-controlled processes such as overt development and mask a wild-type circadian clock.

\section{ACKNOWLEDGMENTS}

This work was supported by grants from the National Institutes of Health to J.J.L. and J.C.D. (GM083336 and GM068087), J.C.D. (GM34985), and the Norris Cotton Cancer Center. L.F.L. is Pew Latin American fellow. We gratefully acknowledge the invaluable services of the Fungal Genetics Stock Center, University of Missouri, Kansas City.

\section{REFERENCES}

Aguirre J., Rios-Momberg M., Hewitt D., and Hansberg W. 2005. Reactive oxygen species and development in microbial eukaryotes. Trends Microbiol. 13: 111.

Aronson B.D., Johnson K.A., and Dunlap J.C. 1994a. The circadian clock locus frequency: A single ORF defines period length and temperature compensation. Proc. Natl. Acad. Sci. 91: 7683.

Aronson B., Johnson K., Loros J.J., and Dunlap J.C. 1994b. Negative feedback defining a circadian clock: Autoregulation in the clock gene frequency. Science 263: 1578.

Arpaia G., Loros J.J., Dunlap J.C., Morelli G., and Macino G. 1993. The interplay of light and the circadian clock: Independent dual regulation of clock-controlled gene $\mathrm{ccg}$-2 (eas). Plant Physiol. 102: 1299.

. 1995. The circadian clock-controlled gene $c c g-1$ is induced by light. Mol. Gen. Genet. 247: 157.

Bailey M.J., Beremand P.D., Hammer R., Reidel E., Thomas T.L., and Cassone V.M. 2004. Transcriptional profiling of circadian patterns of mRNA expression in the chick retina. J. Biol. Chem. 279: 52247.

Bailey-Shrode L. and Ebbole D.J. 2004. The fluffy gene of Neurospora crassa is necessary and sufficient to induce conidiophore development. Genetics 166: 1741.

Ballario P., Talora C., Galli D., Linden H., and Macino G. 1998. Roles in dimerization and blue light photoresponse of the PAS and LOV domains of Neurospora crassa WHITE COLLAR proteins. Mol. Microbiol. 29: 719.

Ballario P., Vittorioso P., Magrelli A., Talora C., Cabibbo A., and Macino G. 1996. White collar-1, a central regulator of bluelight responses in Neurospora crassa, is a zinc-finger protein. EMBO J. 15: 1650.

Balsalobre A., Damiola F., and Schibler U. 1998. A serum shock induces circadian gene expression in mammalian culture cells. Cell 93: 929.

Beadle G.W. and Tatum E.L. 1945. Neurospora. II. Methods of producing and detecting mutations concerned with nutritional requirements. Am. J. Botan. 32: 678.

Belden W.J., Larrondo L.F., Froehlich A.C., Shi M., Chen C.-H., Loros J.J., and Dunlap J.C. 2007. The band mutation in Neurospora crassa is a dominant allele of ras-1 implicating RAS-signaling in circadian output. Genes Dev. 21: 1494.

Bell-Pedersen D. 2000. Understanding circadian rhythmicity in Neurospora crassa: From behavior to genes and back again. Fungal Genet. Biol. 29: 1.

Bell-Pedersen D., Dunlap J.C., and Loros J.J. 1996a. Distinct cisacting elements mediate clock, light, and developmental regulation of the Neurospora crassa eas (ccg-2) gene. Mol. Cell. Biol. 16: 513.

Bell-Pedersen D., Shinohara M., Loros J., and Dunlap J.C. 1996b. Circadian clock-controlled genes isolated from Neurospora crassa are late night to early morning specific. Proc. Natl. Acad. Sci. 93: 13096.

Bünning E. 1973. The physiological clock. Springer-Verlag, New York.

Ceriani M.F., Hogenesch J.B., Yanovsky M., Panda S., Straume M., and Kay S.A. 2002. Genome-wide expression analysis in Drosophila reveals genes controlling circadian behavior. $J$. Neurosci. 22: 9305.

Cheng P., Yang Y., Gardner K.H., and Liu Y. 2002. PAS domainmediated WC-1/WC-2 interaction is essential for maintaining the steady-state level of WC-1 and the function of both proteins in clock and light responses of Neurospora. Mol. Cell. Biol. 22: 517.

Cheng P., He Q., He Q., Wang L., and Liu Y. 2005. Regulation of the Neurospora circadian clock by an RNA helicase. Genes Dev. 19: 234.

Christensen M., Falkeid G., Hauge I., Loros J.J., Dunlap J.C., Lillo C., and Ruoff P. 2004. A frq-independent nitrate reductase rhythm in Neurospora crassa. J. Biol. Rhythms 19: 280.

Collett M.A., Dunlap J.C., and Loros J.J. 2001. Circadian clockspecific roles for the light response protein WHITE COLLAR2. Mol. Cell. Biol. 21: 2619.

Collett M.A., Garceau N., Dunlap J.C., and Loros J.J. 2002. Light 
and clock expression of the Neurospora clock gene frequency is differentially driven by but dependent on WHITE COLLAR2. Genetics 160: 149.

Colot H.V., Loros J.J., and Dunlap J.C. 2005. Temperature-modulated alternative splicing and promoter use in the circadian clock gene frequency. Mol. Biol. Cell 16: 5563.

Correa A. and Bell-Pedersen D. 2002. Distinct signaling pathways from the circadian clock participate in regulation of rhythmic conidiospore development in Neurospora crassa. Eukaryot. Cell 1: 273

Correa A., Lewis Z.A., Greene A.V., March I.J., Gomer R.H., and Bell-Pedersen D. 2003. Multiple oscillators regulate circadian gene expression in Neurospora. Proc. Natl. Acad. Sci. 100: 13597.

Crosthwaite S.C., Dunlap J.C., and Loros J.J. 1997. Neurospora $w c-1$ and $w c-2$ : Transcription, photoresponses, and the origins of circadian rhythmicity. Science 276: 763.

Crosthwaite S.C., Loros J.J., and Dunlap J.C. 1995. Light-induced resetting of a circadian clock is mediated by a rapid increase in frequency transcript. Cell 81: 1003.

D'Autréaux B. and Toledano M. 2007. ROS as signalling molecules: Mechanisms that generate specificity in ROS homeostasis. Nat. Rev. Mol. Cell Biol. 8: 813.

Denault D.L., Loros J.J., and Dunlap J.C. 2001. WC-2 mediates WC-1-FRQ interaction within the PAS protein-linked circadian feedback loop of Neurospora crassa. EMBO J. 20: 109.

dePaula R.M., Lewis Z.A., Greene A.V., Seo K.S., Morgan L.W., Vitalini M.W., Bennett L., Gomer R.H., and Bell-Pedersen D. 2006. Two circadian timing circuits in Neurospora crassa share components and regulate distinct rhythmic processes. J. Biol. Rhythms 21: 159

Diernfellner A.C., Schafmeier T., Merrow M.W., and Brunner M. 2005. Molecular mechanism of temperature sensing by the circadian clock of Neurospora crassa. Genes Dev. 19: 1968.

Dowse H.B., Hall J.C., and Ringo J.M. 1987. Circadian and ultradian rhythms in period mutants of Drosophila melanogaster. Behav. Genet. 17: 19.

Duffield G.E. 2003. DNA microarray analyses of circadian timing: The genomic basis of biological time. J. Neuroendocrinol. 15: 991.

Duffield G.E., Best J.D., Meurers B.H., Bittner A., Loros J.J., and Dunlap J.C. 2002. Circadian programs of transcriptional activation, signaling, and protein turnover revealed by microarray analysis of mammalian cells. Curr. Biol. 12: 551.

Dunlap J.C. 1999. Molecular bases for circadian clocks. Cell 96: 271.

Dunlap J.C. and Loros J.J. 2004. The Neurospora circadian system. J. Biol. Rhythms 19: 414.

2005. Analysis of circadian rhythms in Neurospora: Overview of assays and genetic and molecular biological manipulation. Methods Enzymol. 393: 3.

2006. How fungi keep time: Circadian system in Neurospora and other fungi. Curr. Opin. Microbiol. 9: 579.

Dunlap J.C., Loros J.J., Denault D., Lee K., Froehlich A.F., Colot H., Shi M., and Pregueiro A. 2004. Genetics and molecular biology of circadian rhythms. In Biochemistry and molecular biology: The Mycota III (ed. R. Brambl and G.A. Marzluf), p. 209. Springer-Verlag, Berlin.

Ehret C.F. and Wille J.J. 1970. The photobiology of circadian rhythms in protozoa. In Photobiology of microorganisms (ed. P. Halldal), p. 369. Wiley, New York.

Elvin M., Loros J.J., Dunlap J.C., and Heintzen C. 2005. The PAS/LOV protein VIVID supports a rapidly dampened daytime oscillator that facilitates entrainment of the Neurospora circadian clock. Genes Dev. 19: 2593

Eskin A. 1979. Identification and physiology of circadian pacemakers. Fed. Proc. 38: 2570.

Fagan T., Morse D., and Hastings J.W. 1999. Circadian synthesis of a nuclear-encoded chloroplast glyceraldehyde-3-phosphate dehydrogenase in the dinoflagellate Gonyaulax polyedra is translationally controlled. Biochemistry 38: 7689.

Feldman J. and Hoyle M.N. 1974. A direct comparison between circadian and noncircadian rhythms in Neurospora crassa. Plant Physiol. 53: 928.
Froehlich A.C., Loros J.J., and Dunlap J.C. 2002. White Collar-1, a circadian blue light photoreceptor, binding to the frequency promoter. Science 297: 815.

2003. Rhythmic binding of a WHITE COLLAR containing complex to the frequency promoter is inhibited by FREQUENCY. Proc. Natl. Acad. Sci. 100: 5914.

Fu L., Pelicano H., Liu J., Huang P., and Lee C.-C. 2002. The circadian gene Period2 plays an important role in tumor suppression and DNA damage response in vivo. Cell 111: 41.

Garceau N., Liu Y., Loros J.J., and Dunlap J.C. 1997. Alternative initiation of translation and time-specific phosphorylation yield multiple forms of the essential clock protein FREQUENCY. Cell 89: 469

Gardner G.F. and Feldman J.F. 1981. Temperature compensation of circadian periodicity in clock mutants of Neurospora crassa. Plant Physiol. 68: 1244.

Geva-Zatorsky N., Rosenfeld N., Itzkovitz S., Milo R., Sigal A., Dekel E., Yarnitzky T., Liron Y., Polak P., Lahav G., and Alon U. 2006. Oscillations and variability in the p53 system. Mol. Syst. Biol. 2: 2006.0033.

Gooch V., Mehra A., Larrondo L., Fox J., Touroutoutoudis M., Loros J., and Dunlap J. 2008. Fully codon-optimized luciferase uncovers novel temperature characteristics of the Neurospora clock. Eukaryot. Cell 7: 28.

Granshaw T., Tsukamoto M., and Brody S. 2003. Circadian rhythms in Neurospora crassa: Farnesol or geraniol allow expression of rhythmicity in the otherwise arrhythmic strains frq10, wc-1, and wc-2. J. Biol. Rhythms 18: 287.

Hamblen-Coyle M., Konopka R.J., Zwiebel L.J., Colot H.V., Dowse H.B., Rosbash M., and Hall J.C. 1989. A new mutation at the period locus with some novel effects on circadian rhythms. J. Neurogenet. 5: 229.

Hansberg W. and Aguirre J. 1990. Hyperoxidant states cause microbial cell differentiation by cell isolation from dioxygen. $J$. Theor. Biol. 142: 201.

Harmer S.L., Hogenesch J.B., Straume M., Chang H.-S., Han B., Zhu T., Wang X., Kreps J.A., and Kay S.A. 2000. Orchestrated transcription of key pathways in Arabidopsis by the circadian clock. Science 290: 2110.

Harrison J. and Haber J. 2006. Surviving the breakup: The DNA damage checkpoint. Annu. Rev. Genet. 40: 209.

Hastings J.W. and Sweeney B.M. 1958. A persistent diurnal rhythm of luminescence in Gonyaulax polyedra. Biol. Bull. 115: 440 .

He Q., Cheng P., He Q., and Liu Y. 2005. The COP9 signalosome regulates the Neurospora circadian clock by controlling the stability of the SCFFWD-1 complex. Genes Dev. 19: 1518

He Q., Cheng P., Yang Y., He Q., Yu Q., and Liu Y. 2003. FWD1 mediated degradation of FREQUENCY in Neurospora establishes a conserved mechanism for circadian clock regulation. EMBO J. 22: 4421.

He Q., Cheng P., Yang Y., Wang L., Gardner K., and Liu Y. 2002. White Collar-1, a DNA binding transcription factor and a light sensor. Science 297: 840.

Heintzen C. and Liu Y. 2007. The Neurospora crassa circadian clock. Adv. Genet. 58: 25.

Heintzen C., Loros J.J., and Dunlap J.C. 2001. The PAS protein VIVID defines a clock-associated feedback loop that represses light input, modulates gating, and regulates clock resetting. Cell 104: 453 .

Heo J. and Campbell S.L. 2006. Ras regulation by reactive oxygen and nitrogen species. Biochemistry 45: 2200.

Hunt S.M., Elvin M., Crosthwaite S.K., and Heintzen C. 2007. The PAS/LOV protein VIVID controls temperature compensation of circadian clock phase and development in Neurospora crassa. Genes Dev. 21: 1964.

Irani K., Xia Y., Zweier J.L., Sollott S.J., Der C.J., Fearon E.R., Sundaresan M., Finkel T., and Goldschmidt-Clermont P.J. 1997. Mitogenic signaling mediated by oxidants in Ras-transformed fibroblasts. Science 275: 1649.

Iwasaki H. and Dunlap J.C. 2000. Microbial circadian oscillatory systems in Neurospora and Synechococcus: Models for cellular clocks. Curr. Opin. Microbiol. 3: 189.

Iwasaki T., Nakahama K., Nagano M., Fujioka A., Ohyanagi H., 
and Shigeyoshi Y. 2004. A partial hepatectomy results in altered expression of clock-related and cyclic glyceraldehyde 3-phosphate dehydrogenase (GAPDH) genes. Life Sci. 74: 3093.

Kamphuis W., Cailotto C., Dijk F., Bergen A., and Buijs R.M 2005. Circadian expression of clock genes and clock-controlled genes in the rat retina. Biochem. Biophys. Res. Commun. 330: 18

Kim W., Fujiwara S., Suh S., Kim J., Kim Y., Han L., David K., Putterill J., Nam H., and Somers D.E. 2007. ZEITLUPE is a circadian photoreceptor stabilized by GIGANTEA in blue light. Nature 449: 356.

Kobayashi H., Oishi K., Hanai S., and Ishida N. 2004. Effect of feeding on peripheral circadian rhythms and behaviour in mammals. Genes Cells 9: 857.

Kornmann B., Preitner N., Rifat D., Fleury-Olela F., and Schibler U. 2001. Analysis of circadian liver gene expression by ADDER, a highly sensitive method for the display of differentially expressed mRNAs. Nucleic Acids Res. 29: E51.

Kramer C., Loros J.J., Dunlap J.C., and Crosthwaite S.K. 2003. Role for antisense RNA in regulating circadian clock function in Neurospora crassa. Nature 421: 948.

Lakin-Thomas P. 1996. Effects of choline depletion on the circadian rhythm in Neurospora crassa. Biol. Rhythm Res. 27: 12.

. 1998. Choline depletion, frq mutations, and temperature compensation of the circadian rhythm in Neurospora crassa. $J$. Biol. Rhythms 13: 268

. 2006a. Circadian clock genes frequency and white collar1 are not essential for entrainment to temperature cycles in Neurospora crassa. Proc. Natl. Acad. Sci. 103: 4469.

. 2006b. Transcriptional feedback oscillators: Maybe, maybe not. J. Biol. Rhythms 21: 83.

Lakin-Thomas P.L. and Brody S. 2000. Circadian rhythms in Neurospora crassa: Lipid deficiencies restore robust rhythmicity to null frequency and white-collar mutants. Proc. Natl. Acad. Sci. 97: 256.

Lee C.C. 2005. The circadian clock and tumor suppression by mammalian period genes. Methods Enzymol. 393: 852.

Lee K., Dunlap J.C., and Loros J.J. 2003. Roles for WHITE COLLAR-1 in circadian and general photoperception in Neurospora crassa. Genetics 163: 103.

Lev Bar-Or R., Maya R., Segel L., Alon U., Levine A., and Oren M. 2000. Generation of oscillations by the p53-Mdm2 feedback loop: A theoretical and experimental study. Proc. Natl. Acad. Sci. 97: 11250

Lillo C., Meyer C., and Ruoff P. 2001. The nitrate reductase circadian system. Plant Physiol. 125: 1554

Linden H. and Macino G. 1997. White collar-2, a partner in bluelight signal transduction, controlling expression of light-regulated genes in Neurospora crassa. EMBO J. 16: 98.

Linden H., Ballario P., and Macino G. 1997. Blue light regulation in Neurospora crassa. Fungal Genet. Biol. 22: 141.

Liu A., Welsh D., Ko C., Tran H., Zhang E., Priest A., Buhr E., Singer O., Meeker K., Verma I., Doyle F.J., III., Takahashi J., and Kay S. 2007. Intercellular coupling confers robustness against mutations in the SCN circadian clock network. Cell 129: 605 .

Liu Y. and Bell-Pedersen D. 2006. Circadian rhythms in Neurospora crassa and other filamentous fungi. Eukaryot. Cell 5: 1184.

Liu Y., Loros J., and Dunlap J.C. 2000. Phosphorylation of the Neurospora clock protein FREQUENCY determines its degradation rate and strongly influences the period length of the circadian clock. Proc. Natl. Acad. Sci. 97: 234.

Liu Y., Merrow M., Loros J.J., and Dunlap J.C. 1998. How temperature changes reset a circadian oscillator. Science 281: 825.

Liu Y., Tsinoremas N., Johnson C., Lebdeva N., Golden S., Ishiura M., and Kondo T. 1995. Circadian orchestration of gene expression in cyanobacteria. Genes Dev. 9: 1469.

Lombardi L., Schneider K., Tsukamoto M., and Brody S. 2007. Circadian rhythms in Neurospora crassa: Clock mutant effects in the absence of a frq-based oscillator. Genetics 175: 1175 .

Loros J.J. 1984. "Studies on frq-9, a recessive circadian clock mutant of Neurospora crassa." Ph.D. thesis, University of California, Santa Cruz.
Loros J.J. and Dunlap J.C. 1991. Neurospora crassa clock-controlled genes are regulated at the level of transcription. Mol. Cell. Biol. 11: 558 .

. 2001. Genetic and molecular analysis of circadian rhythms in Neurospora. Annu. Rev. Physiol. 63: 757.

. 2006. Circadian rhythms, photobiology, and functional genomics in Neurospora. In Fungal genomics: The Mycota (ed. A.J.P. Brown), vol. 13, p.53. Springer-Verlag, Berlin.

Loros J.J. and Feldman J.F. 1986. Loss of temperature compensation of circadian period length in the frq-9 mutant of Neurospora crassa. J. Biol. Rhythms 1: 187.

Loros J.J., Denome S.A., and Dunlap J.C. 1989. Molecular cloning of genes under the control of the circadian clock in Neurospora. Science 243: 385.

Loros J.J., Hastings J.W., and Schibler U. 2003. Adapting to life on a rotating world at the gene expression level. In Chronobiology: Biological timekeeping (ed. J.C. Dunlap et al.), p. 254. Sinauer Associates, Sunderland, Massachusetts.

Loros J.J., Richman A., and Feldman J.F. 1986. A recessive circadian clock mutant at the frq locus in Neurospora crassa. Genetics 114: 1095.

Matsuoka S., Huang M., and Elledge S.J. 1998. Linkage of ATM to cell cycle regulation by the Chk2 protein kinase. Science 282: 1893

Mattern D. and Brody S. 1979. Circadian rhythms in Neurospora crassa: Effects of unsaturated fatty acids. J. Bacteriol. 139: 977.

Merrow M., Brunner M., and Roenneberg T. 1999. Assignment of circadian function for the Neurospora clock gene frequency. Nature 399: 584.

Merrow M., Garceau N., and Dunlap J.C. 1997. Dissection of a circadian oscillation into discrete domains. Proc. Natl. Acad. Sci. 94: 3877

Merrow M., Roenneberg T., Macino G., and Franchi L. 2001. A fungus among us: The Neurospora crassa circadian system. Semin. Cell Dev. Biol. 12: 279.

Mitin N., Rossman K., and Der C. 2005. Signaling interplay in Ras superfamily function. Curr. Biol. 15: R563.

Morgan L.W., Greene A.V., and Bell-Pedersen D. 2003. Circadian and light-induced expression of luciferase in Neurospora crassa. Fungal Genet. Biol. 38: 327.

Nakashima H. 1981. A liquid culture system for the biochemical analysis of the circadian clock of Neurospora. Plant Cell Physiol. 22: 231.

Nowrousian M., Duffield G.E., Loros J.J., and Dunlap J.C. 2003. The frequency gene is required for temperature-dependent regulation of many clock-controlled genes in Neurospora crassa. Genetics 164: 922.

Okamura H., Miyake S., Sumi Y., Yamaguchi S., Yasui A., Muijtjens M., Hoeijmakers J.H., and van der Horst G.T. 1999. Photic induction of mPer1 and mPer2 in cry-deficient mice lacking a biological clock. Science 286: 2531.

Panda S., Antoch M.P., Miller B., Su A., Schook A., Straume M., Schultz P., Kay S., Takahashi J., and Hogenesch J.B. 2002. Coordinated transcription of key pathways in the mouse by the circadian clock. Cell 109: 307.

Perlman J., Nakashima H., and Feldman J. 1981. Assay and characteristics of circadian rhythmicity in liquid cultures of Neurospora crassa. Plant Physiol. 67: 404.

Pittendrigh C.S. 1981. Circadian systems: Entrainment. In Biological rhythms: Handbook of behavioral neurobiology (ed. J. Aschoff), vol. 4, p. 95. Plenum, New York.

Pittendrigh C. and Bruce V. 1959. Daily rhythms as coupled oscillator systems and their relation to thermoperiodism and photoperiodism. In Photoperiodism and related phenomena in plants and animals (ed. R.B. Withrow), p. 475. AAAS, Washington D.C.

Pregueiro A., Liu Q., Baker C., Dunlap J.C., and Loros J.J. 2006. The Neurospora checkpoint kinase 2: A regulatory link between the circadian and cell cycles. Science 313: 644.

Pregueiro A.M., Price-Lloyd N., Bell-Pedersen D., Heintzen C., Loros J.J., and Dunlap J.C. 2005. Assignment of an essential role for the Neurospora frequency gene in circadian entrainment to temperature cycles. Proc. Natl. Acad. Sci. 102: 2210. 
Price-Lloyd N., Elvin M., and Heintzen C. 2005. Synchronizing the Neurospora crassa circadian clock with the rhythmic environment. Biochem. Soc. Trans. 33: 949.

Ramalho C.B., Hastings J.W., and Colepicolo P. 1995. Circadian oscillation of nitrate reductase activity in Gonyaulax polyedra is due to changes in cellular protein levels. Plant Physiol. 107: 225.

Roenneberg T. and Merrow M. 1998. Molecular circadian oscillators: An alternative hypothesis. J. Biol. Rhythms 13: 167.

Roenneberg T., Dragovic Z., and Merrow M. 2005. Demasking biological oscillators: Properties and principles of entrainment exemplified by the Neurospora circadian clock. Proc. Natl. Acad. Sci. 102: 7742.

Ryan F.J., Beadle G.W., and Tatum E.L. 1943. The tube method for measuring the growth rate of Neurospora. Am. J. Bot. 30: 784 .

Sargent M.L., Briggs W.R., and Woodward D.O. 1966. The circadian nature of a rhythm expressed by an invertaseless strain of Neurospora crassa. Plant Physiol. 41: 1343.

Schafmeier T., Kaldi K., Diernfellner A., Mohr C., and Brunner M. 2006. Phosphorylation-dependent maturation of Neurospora circadian clock protein from a nuclear repressor towards a cytoplasmic activator. Genes Dev. 20: 297.

Schwerdtfeger C. and Linden H. 2003. VIVID is a flavoprotein and serves as a fungal blue light photoreceptor for photoadaptation. EMBO J. 22: 4846.

Schwerdtfeger C., Loros J.J., Dunlap J.C., and Linden H. 2003. VIVID is a flavoprotein and serves as a fungal blue light photoreceptor for photoadaptation. Fungal Genet. Newsl. (suppl.) 50: (Abstr. 236.)

Shi M., Larrondo L.F., Loros J.J., and Dunlap J.C. 2007. A developmental cycle masks output from the circadian oscillator under conditions of choline deficiency in Neurospora. Proc. Natl. Acad. Sci. 104: 20102.

Shigeyoshi Y., Taguchi K., Yamamoto S., Takeida S., Yan L., Tei H., Moriya S., Shibata S., Loros J.J., Dunlap J.C., and Okamura H. 1997. Light-induced resetting of a mammalian circadian clock is associated with rapid induction of the $\mathrm{mPerl}$ transcript. Cell 91: 1043.

Shinohara M., Loros J.J., and Dunlap J.C. 1998. Glyceraldehyde- 3-phosphate dehydrogenase is regulated on a daily basis by the circadian clock. J. Biol. Chem. 273: 446.

Storch K., Paz C., Signorovitch J., Raviola E., Pawlyk B., Li T., and Weitz C. 2007. Intrinsic circadian clock of the mammalian retina: Importance for retinal processing of visual information. Cell Tissue Res. 130: 730.

Sussman A.S., Durkee T., and Lowrey R.J. 1965. A model for rhythmic and temperature-independent growth in the "clock" mutants of Neurospora. Mycopathol. Mycol. Appl. 25: 381.

Sussman A.S., Lowrey R.J., and Durkee T. 1964. Morphology and genetics of a periodic colonial mutant of Neurospora crassa. Am. J. Bot. 51: 243.

Talora C., Franchi L., Linden H., Ballario P., and Macino G. 1999. Role of a white collar-1-white collar-2 complex in blue-light signal transduction. EMBO J. 18: 4961.

Temme A., Ott T., Haberberger T., Traub O., and Willecke K. 2000. Acute-phase response and circadian expression of connexin26 are not altered in connexin32-deficient mouse liver. Cell Tissue Res. 300: 111.

Tu B.P. and McKnight S.L. 2006. Metabolic cycles as an underlying basis of biological oscillations. Nat. Rev. Mol. Cell Biol. 7: 696

Vitalini M.W., de Paula R.M., Park W.D., and Bell-Pedersen D. 2006. The rhythms of life: Circadian output pathways in Neurospora. J. Biol. Rhythms 21: 432.

Wijnen H. and Young M.W. 2006. Interplay of circadian clocks and metabolic rhythms. Annu. Rev. Genet. 40: 409.

Yoshida Y. and Hasunuma K. 2004. Reactive oxygen species affect photomorphogenesis in Neurospora crassa. J. Biol. Chem. 279: 6986.

Zhu H., Nowrousian M., Kupfer D., Colot H., Berrocal-Tito G., Lai H., Bell-Pedersen D., Roe B., Loros J.J., and Dunlap J.C. 2001. Analysis of expressed sequence tags from two starvation, time-of-day-specific libraries of Neurospora crassa reveals novel clock-controlled genes. Genetics 157: 1057.

Zoltowski B.D., Schwerdtfeger C., Widom J., Loros J.J., Bilwes A.M., Dunlap J.C., and Crane B.R. 2007. Conformational switching in the fungal light sensor Vivid. Science 316: 1054. 


\title{
$8_{\text {SYMPOS }}^{\infty}$ Cold Spring Harbor Symposia SYMPOSIA on Quantitative Biology
}

\section{Circadian Output, Input, and Intracellular Oscillators: Insights into the Circadian Systems of Single Cells}

\author{
J. J. Loros, J. C. Dunlap, L. F. Larrondo, et al.
}

Cold Spring Harb Symp Quant Biol 2007 72: 201-214

Access the most recent version at doi:10.1101/sqb.2007.72.067

References This article cites 129 articles, 63 of which can be accessed free at: http://symposium.cshlp.org/content/72/201.full.html\#ref-list-1

\section{License}

Email Alerting Service
Receive free email alerts when new articles cite this article - sign up in the box at the top right corner of the article or click here. 